trial should have sufficient methodological rigor such that it can be expected to contribute to our stock of knowledge. Unfortunately, it appears that many trials may not meet these criteria, regardless of whether participation is informed and voluntary.

Michel Shamy, M.D.

University of Ottawa

Ottawa, ON, Canada

mshamy@toh.on.ca

Mark Fedyk, Ph.D.

Mount Allison University

Sackville, NB, Canada

No potential conflict of interest relevant to this letter was reported.

DOI: 10.1056/NEJMc1615364

THE AUTHORS REPLY: Paton raises the thorny issue of attribution of primacy. We were aware of multiple observational studies indicating favorable outcomes with the use of antihypertensive agents in patients with malignant hypertension. ${ }^{1}$ In reexamining the literature, we did indeed find an important trial involving patients with severe hypertension (diastolic blood pressure, $>130 \mathrm{~mm} \mathrm{Hg}$ ) who were randomly assigned to antihypertensive therapy (with reserpine, chlorothiazide, or hydrochlorothiazide-guanethidine) or matching placebos. $^{2}$ We will resist calling this the first trial and instead use the term "early."
Shamy and Fedyk appropriately remind us that there are special situations in responsible clinical research in which informed consent may be waived. Their point was recently illustrated in the Informed Fresh versus Old Red Cell Management (INFORM) trial. ${ }^{3}$ In this trial, each site's ethics committee waived the need for patient consent "because all the patients received treatment that was consistent with the current standard of care." ${ }^{3}$ We agree with their additional points indicating that obtaining consent is only one of the many responsibilities of investigators in conducting quality clinical investigation.

Marc A. Pfeffer, M.D., Ph.D.

Brigham and Women's Hospital Boston, MA

mpfeffer@rics.bwh.harvard.edu

John J.V. McMurray, M.D.

University of Glasgow

Glasgow, United Kingdom

Since publication of their article, the authors report no further potential conflict of interest.

1. Smirk FH. The prognosis of untreated and of treated hypertension and advantages of early treatment. Am Heart J 1972;83: 825-40.

2. Wolff FW, Lindeman RD. Effects of treatment in hypertension: results of a controlled study. J Chronic Dis 1966;19:227-40. 3. Heddle NM, Cook RJ, Arnold DM, et al. Effect of short-term vs. long-term blood storage on mortality after transfusion. $\mathrm{N}$ Engl J Med 2016;375:1937-45.

DOI: 10.1056/NEJMc1615364

\title{
Myocarditis with Immune Checkpoint Blockade
}

TO THE EDITOR: In their report on cardiotoxicity associated with immune checkpoint blockade, Johnson et al. (Nov. 3 issue) ${ }^{1}$ describe two patients with melanoma in whom fatal myocarditis developed after treatment with ipilimumab and nivolumab. In addition, other cases of cardiotoxicity associated with such treatment have been reported. ${ }^{2,3}$ However, such cardiac events remain exceptional in phase 3 trials of immune checkpoint inhibitors (Table 1).

The wide spectrum of immune-related adverse events is making it difficult for clinicians to properly evaluate rare but sometimes fatal events. To address this issue, we initiated a pharmacovigilance registry at Gustave Roussy called REISAMIC (Registre des Effets Indésirables Sévères des Anticorps Monoclonaux Immunomodulateurs en Can- cérologie) ${ }^{4}$ to prospectively collect data on such adverse events.

Over an 18-month period, 388 patients were included in the registry. To date, only one cardiovascular adverse event (atrial fibrillation) has been registered and considered to be possibly related to immunotherapy. No case of heart failure or complete heart block was observed. As reported by Johnson et al., our data confirm a very low frequency of cardiac adverse events related to immunotherapy. On the basis of our experience and reported frequencies, we currently limit our cardiac evaluation to a baseline electrocardiogram in the absence of a history of cardiovascular events. We believe it is premature to recommend more comprehensive cardiac monitoring to the oncologist com- 


\begin{tabular}{|c|c|c|c|c|}
\hline Study and Year & Tumor Type & Drug & $\begin{array}{l}\text { Exposed } \\
\text { Patients }\end{array}$ & $\begin{array}{c}\text { Reported Cases of } \\
\text { Cardiovascular Toxicity }\end{array}$ \\
\hline & & & no. & no. (\%) \\
\hline All studies & & & 5347 & $10(0.19)$ \\
\hline Hodi et al., 2010 & Melanoma & Ipilimumab & 511 & 0 \\
\hline Robert et al., 2011 & Melanoma & Ipilimumab & 247 & 0 \\
\hline Weber et al., 2015 & Melanoma & Nivolumab & 268 & 0 \\
\hline Robert et al., 2015 & Melanoma & Nivolumab & 206 & 1 case of hypotension $(0.49)$ \\
\hline Robert et al., 2015 & Melanoma & $\begin{array}{l}\text { Pembrolizumab or } \\
\text { ipilimumab }\end{array}$ & 811 & $\begin{array}{l}1 \text { cardiac arrest associated with } \\
\text { metabolic imbalances from } \\
\text { ipilimumab-induced diar- } \\
\text { rhea; } 4 \text { cases of hyperten- } \\
\text { sion }(0.62)\end{array}$ \\
\hline Larkin et al., 2015 & Melanoma & $\begin{array}{l}\text { Nivolumab, ipilimumab, } \\
\text { or nivolumab plus } \\
\text { ipilimumab }\end{array}$ & 937 & 0 \\
\hline $\begin{array}{l}\text { Eggermont et al., } \\
2015 \text { and } 2016\end{array}$ & Melanoma (adjuvant) & Ipilimumab & 471 & 1 case of myocarditis $(0.21)$ \\
\hline Borghaei et al., 2015 & $\begin{array}{l}\text { Non-squamous non-small- } \\
\text { cell lung cancer }\end{array}$ & Nivolumab & 287 & $\begin{array}{l}1 \text { case of cardiac tamponade; } \\
1 \text { case of pericardial effu- } \\
\text { sion }(0.70)\end{array}$ \\
\hline Brahmer et al., 2015 & $\begin{array}{l}\text { Squamous non-small-cell } \\
\text { lung cancer }\end{array}$ & Nivolumab & 131 & 0 \\
\hline Reck et al., 2016 & Non-small-cell lung cancer & Pembrolizumab & 154 & 0 \\
\hline Herbst et al., 2016 & Non-small-cell lung cancer & Pembrolizumab & 682 & $\begin{array}{l}1 \text { case of myocardial infarction } \\
(0.15)\end{array}$ \\
\hline Motzer et al., 2015 & Renal-cell carcinoma & Nivolumab & 406 & 0 \\
\hline Ferris et al., 2016 & $\begin{array}{l}\text { Head and neck squamous- } \\
\text { cell carcinoma }\end{array}$ & Nivolumab & 236 & 0 \\
\hline
\end{tabular}

* A complete reference list of the studies is provided in the Supplementary Appendix, available at NEJM.org.

munity aside from that performed in clinical studies.

Stéphane Ederhy, M.D.

Hôpital Saint-Antoine

Paris, France

Anne-Laure Voisin, Pharm.D.

Stéphane Champiat, M.D.

Gustave Roussy

Villejuif, France

champiat@gmail.com

Dr. Champiat reports receiving consulting and lecture fees from Bristol-Myers Squibb, Janssen, Merck Sharp \& Dohme, and Roche. No other potential conflict of interest relevant to this letter was reported.

1. Johnson DB, Balko JM, Compton ML, et al. Fulminant myocarditis with combination immune checkpoint blockade. N Engl J Med 2016;375:1749-55.

2. Gibson R, Delaune J, Szady A, Markham M. Suspected autoimmune myocarditis and cardiac conduction abnormalities with nivolumab therapy for non-small cell lung cancer. BMJ Case Rep 2016;2016:2016216228.

3. Heinzerling L, Ott PA, Hodi FS, et al. Cardiotoxicity associated with CTLA4 and PD1 blocking immunotherapy. J Immunother Cancer 2016;4:50.

4. Champiat S, Lambotte O, Barreau E, et al. Management of immune checkpoint blockade dysimmune toxicities: a collaborative position paper. Ann Oncol 2016;27:559-74.

DOI: 10.1056/NEJMc1615251

TO THE EDITOR: In their discussion of fulminant myocarditis and complete heart block during immune checkpoint therapy, Johnson et al. do not discuss the possible role of circulating anticonductive tissue autoantibodies (ACTA) in the pathogenesis of the sudden heart block and myocarditis. ${ }^{1}$ Since it is not known which autoantigens (other than troponin I, which was tested by 
the authors) could be involved in such a condition, it would be interesting to recheck the patients' serum for the presence of circulating ACTA using an indirect immunofluorescence assay, as described by our group. ${ }^{2}$ A possible immune response against the conductive system is suggested by the reported lymphocytic infiltrate involving the cardiac sinus, the atrioventricular node, and the esophageal muscle. In our study, the patient with circulating ACTA had not only heart block but also intestinal pseudo-obstruction, with the latter probably caused by an impairment in the "gut pacemaker" and intestinal conductive system. ${ }^{3}$

Giacomo Caio, M.D., Ph.D.

Massachusetts General Hospital

Boston, MA

gcaio@mgh.harvard.edu

No potential conflict of interest relevant to this letter was reported.

1. Fairfax A, Doniach D. Autoantibodies to cardiac conducting tissue and their characterization by immunofluorescence. Clin Exp Immunol 1976;23:1-8.

2. Caio G, Volta U, Cerrato E, et al. Detection of anticonductive tissue autoantibodies in a patient with chronic intestinal pseudoobstruction and sick sinus syndrome. Eur J Gastroenterol Hepatol 2013;25:1358-63.

3. Huizinga JD, Lammers WJ. Gut peristalsis is governed by a multitude of cooperating mechanisms. Am J Physiol Gastrointest Liver Physiol 2009;296:G1-G8.

DOI: 10.1056/NEJMc1615251

THE AUTHORS REPLY: We completely agree with Ederhy and colleagues that cardiac complications are rare with immune checkpoint inhibitors when the drugs are used as single agents. However, our current data suggest that such complications may be more frequent with combination therapy and that simple cardiac screening may be appropriate. There are several important considerations regarding the cardiovascular safety data generated from oncology clinical trials, as Ederhy et al. have compiled in Table 1 of their letter. First, oncology trials often exclude "real world" patients who have a previous cardiac history and may be at increased risk for cardiac complications. Second, there are inherent limitations in the manner in which cardiac toxicity is adjudicated in oncology trials. Almost no checkpoint-inhibitor trial to date has screened patients for myocarditis. Third, myocarditis is often a diagnosis of exclusion and can be missed if there is no active monitoring for this toxicity. Finally, the cases of myocarditis associated with checkpoint inhibitors that we have seen are characterized less by the typical features of cardiomyopathy and more by electrocardiographic instability, which may be more difficult to detect.

Caio's point is well taken regarding the possibility of detection of autoantibodies in our patients. However, it is important to note that the presence of autoantibodies does not prove causation. In our patients, we looked for antibody deposits in the inflamed tissues but did not find any evidence of antibody deposition. Instead, we observed a dense cellular infiltrate composed of $\mathrm{T}$ cells and macrophages in the heart and skeletal muscle. We certainly agree that further research in this area should include a detailed analysis of circulating antibodies.

Javid J. Moslehi, M.D.

Douglas B. Johnson, M.D.

Jeffrey A. Sosman, M.D.

Vanderbilt School of Medicine

Nashville, TN

javid.moslehi@vanderbilt.edu

Since publication of their article, the authors report no further potential conflict of interest.

DOI: 10.1056/NEJMc1615251

\section{Variant Creutzfeldt-Jakob Disease in a Patient with Heterozygosity at PRNP Codon 129}

TO THE EDITOR: Prions cause lethal neurodegenerative diseases in mammals and are composed of multichain assemblies of misfolded hostencoded cellular prion protein (PrP). A common polymorphism at codon 129 of the PrP gene (PRNP), where either methionine (M) or valine (V) is encoded, affects the susceptibility to prion disease, as well as the incubation period ${ }^{1}$ and clinical phenotype of prion disease. Human in- fection with the epizootic prion disease bovine spongiform encephalopathy resulted in variant Creutzfeldt-Jakob disease, which provoked a public health crisis in the United Kingdom and other regions. All definite cases of variant Creutzfeldt-Jakob disease to date have occurred in patients with the MM genotype at PRNP codon $129 .{ }^{1}$

A 36-year-old man was referred to the United 